16 a 18 de outubro de 2019 - Campinas | Brasil

\title{
Tecnologias sociais voltadas à geração de renda na Argentina, Brasil, Colômbia e México: identificação de desafios e fatores de sucesso para sua efetiva reaplicação em interface com o fenômeno das redes
}

\section{Leandra Wanille de Oliveira Meursing ${ }^{*}$ Paulo Van Noije}

\begin{abstract}
Resumo
Frente à dinâmica excludente da economia capitalista e tendo em vista que a tecnologia não é neutra, faz-se necessário reverter essa lógica para uma baseada na cooperação. Contrapondo-se a esse modelo convencional, emerge o conceito de Tecnologia Social (TS). Nesse sentido, a proposta do projeto é estudar qual a influência das redes sob a reaplicabilidade das TSs que geram renda na Argentina, Brasil, Colômbia e México, entendendo que a baixa/alta reaplicabilidade pode estar relacionada com a conectividade da rede que se articula entorno à TS, além de identificar os pré-requisitos para reaplicá-las, principais desafios e fatores de sucesso que perpassam essa temática.
\end{abstract}

\section{Palavras-chave:}

Tecnologia social, geração de renda, redes.

\section{Introdução}

Vivemos em um contexto tecnológico pautado na predominância do modelo convencional, em que a tecnologia exerce um papel relevante no desenvolvimento dos países, já que a dinâmica técnica possibilita uma maior acumulação de capital. Entretanto, esse modelo tem se mostrado ineficaz na provisão das condições dignas aos cidadãos, ganhando força o estudo e disseminação de outros padrões, como a Economia Solidária (ES) e as Tecnologias Sociais (TS), vistas como forma de superação e transformação social. Segundo site do Banco do Brasil ${ }^{1}$ (2019)1, TS "compreende produtos, técnicas e/ou metodologias reaplicáveis, desenvolvidas na interação com a comunidade e que representem efetivas soluções de transformação social". Partindo do pressuposto de que existem diversas experiências de tecnologia social, essa pesquisa visa realizar um estudo aprofundado sobre aquelas que geram trabalho e renda na Argentina, Brasil, Colômbia e México, países da América Latina, considerada um espaço geográfico com desigualdade estrutural (CEPAL, 2017)2. Para a elaboração do projeto, foram encontradas 174 experiências de TSs, das quais quatro foram selecionadas. A análise também será feita da perspectiva da reaplicabilidade em interface com o fenômeno das redes formais/informais que se articulam entorno à TS, compreendendo-se que há uma diversidade de atores dotados de conhecimento tácito. Trata-se, assim, de uma pesquisa teórica, com base em revisão bibliográfica e questionários/entrevistas com os atores envolvidos nas experiências levantadas.

\section{Resultados e Discussão}

O presente estudo integrou projeto de pesquisa desenvolvido no âmbito do Laboratório de Estudos do Setor Público (LESP) - coordenado por quatro docentes do curso de Administração Pública da Faculdade de Ciências Aplicadas da Universidade Estadual de Campinas (FCA/Unicamp) - com a participação de nove estudantes de Graduação e de dois pós-graduandos. Tendo como tema principal "Tecnologia Social na América Latina" aplicada aos setores de alimentação; geração de renda; habitação; e meio ambiente, recursos hídricos e energia. Esta pesquisa se concentrou somente em TSs voltadas à geração de renda. Para selecionar as experiências, primeiro se recorreu à bases de dados online, sendo encontradas 174 TSs. Posteriormente, com base em um filtro conceitual, foram selecionadas somente aquelas que se caracterizavam como produto ou técnica, restando 121 TSs. Destas, foram selecionadas quatro para esta análise: "Sistemas constructivos em madera: desarollo de pórticos y cabreadas para el agregado de valor a la madera de pino ponderosa" (Argentina); "Aquecedor Solar Ecológico" (Brasil); "Comunidades Sostenibles" (Colômbia) e "Familia Rural Inteligente" (México). Na tabela 1 que segue pode-se ter um resumo dos desafios e fatores de sucesso encontrados ao analisar essas TSs.

Tabela 1. Desafios e fatores de sucessos encontrados.

\begin{tabular}{|c|c|}
\hline Desafios & Fatores de sucesso \\
\hline - Associação da TS a & - Método "faça você mesmo"; \\
pessoas sem recursos & - Utilização de ferramentas \\
financeiros (estigma); & básicas e de baixo custo; \\
- Descontinuidade em & - Facilidade de construção; \\
decorrência da & - Incentivo do governo; \\
transição de governo; & - Sem necessidade de \\
- Falta de & investimento alto de capital; \\
financiamento. & - Uso de recurso local. \\
\hline
\end{tabular}

Fonte: Elaboração própria, 2019.

\section{Conclusões}

A partir da análise feita até o presente momento, concluise que o incentivo do governo é fundamental na difusão destas experiências, além de que estabelecer uma comunicação verbal eficiente entre as organizações da rede pode vir a ampliar sua conectividade.

\section{Agradecimentos}

Agradeço ao Conselho Nacional de Desenvolvimento Científico e Tecnológico (CNPQ).

\footnotetext{
${ }^{1}$ BANCO DO BRASIL. Tecnologia Social. Disponível em:

$<$ http://tecnologiasocial.fbb.org.br/tecnologiasocial/o-que-e/tecnologiasocial/o-que-e-tecnologia-social.htm > Acesso em: 07 jul. de 2019.
}

${ }^{2}$ CEPAL. A elevada desigualdade na América Latina constitui um obstáculo ao desenvolvimento sustentável. Disponível em:

<https://www.cepal.org/pt-br/comunicados/cepal-elevada-desigualdadeamerica-latina-constitui-obstaculo-o-desenvolvimento> Acesso em 17 de Abril de 2018. 